Quantitative Analysis of Cell Organization in the External Region of the Olive Fruit Author(s): Sof iene B. M. Hammami and Hava F. Rapoport

Source: International Journal of Plant Sciences, Vol. 173, No. 9 (November/December 2012), pp. 993-1004

Published by: The University of Chicago Press

Stable URL: http://www.jstor.org/stable/10.1086/667610

Accessed: 12/02/2014 03:13

Your use of the JSTOR archive indicates your acceptance of the Terms \& Conditions of Use, available at http://www.jstor.org/page/info/about/policies/terms.jsp

JSTOR is a not-for-profit service that helps scholars, researchers, and students discover, use, and build upon a wide range of content in a trusted digital archive. We use information technology and tools to increase productivity and facilitate new forms of scholarship. For more information about JSTOR, please contact support@ jstor.org. 


\title{
QUANTITATIVE ANALYSIS OF CELL ORGANIZATION IN THE EXTERNAL REGION OF THE OLIVE FRUIT
}

\author{
Sofiene B. M. Hammami* and Hava F. Rapoport ${ }^{1, *}$ \\ *Instituto de Agricultura Sostenible, IAS-CSIC, P.O. Box 4084, 14080 Cordoba, Spain
}

\begin{abstract}
Definitions of the cells that constitute the exocarp or exterior tissue of fleshy fruits are often vague, sometimes providing contradictory descriptions of the epidermis plus none or varying numbers of underlying cell layers for the same species. This study uses a morphometric approach to investigate how cell dimensions, cell number, and their relation with genetically based fruit size differences can contribute to a characterization of tissue organization in the external fruit region, using the olive drupe as an example. We determined cell area, radial and tangential widths, and cell number in the epidermis and 20 subepidermal cell layers of mature fruits of four olive cultivars that range in fruit size. Variation of these measurements among cell layers and the implied cellular contributions to fruit expansion revealed two different subepidermal regions, but with constant widths and layer numbers for all cultivars: (1) the first four cell layers (1-4), which have similar behavior to the epidermis; and (2) the following five cell layers (5-9), which are more similar to the mesocarp. The results provide new insights about cell patterns in the external region of the olive fruit and suggest that layers 1-4 together with the epidermis may act as a multiseriate exocarp and layers 5-9 may act as an outer mesocarp.
\end{abstract}

Keywords: exocarp, mesocarp, cell size, cell number, image analysis, Olea europaea L.

\section{Introduction}

Drupe fruits, a type of fleshy fruit, are characterized by a thin, protective exocarp or epicarp; a fleshy mesocarp; and an inedible, stony endocarp surrounding the seed (Roth 1977). Of these tissues, research in fruit developmental biology has mainly evaluated the mesocarp and the endocarp, the two principal tissues in terms of size and energetic cost, while the exocarp has largely been neglected (Bollard 1970; Coombe 1976). Recent studies indicate the fundamental role of the exocarp in fruit growth and development, in particular, the high cell division and metabolic activity observed in this tissue (Bargel and Neinhuis 2005; Lemaire-Chamley et al. 2005; Schlosser et al. 2008; Fu et al. 2010). The exocarp tissue is also thought to play key roles in fruit quality and the interaction between fruits and their environment (Knee 2002; Jeffree 2006; Mintz-Oron et al. 2008). One of the obstacles to exploring and accurately interpreting the role of the exocarp in fruit biology is the difficulty in defining the limit between the exocarp and the mesocarp, for example, to facilitate visually distinguishing between parenchymatous mesocarp and sclerified endocarp tissues.

The fleshy fruit exocarp is principally formed by the epidermal cells and their cuticle, but subepidermal layers may also be included (Roth 1977). Multiseriate exocarp definitions are usually based on the interpretation of a morphologically distinct subepidermal tissue, sometimes called a hypodermis, that differs from the mesocarp in cell size (either larger or

${ }^{1}$ Author for correspondence; e-mail: hrapoport@ias.csic.es.

Manuscript received February 2012; revised manuscript received June 2012. smaller), metabolism, and/or form (shape, cell wall characteristics; Sterling 1953; Considine and Knox 1981; Lavee 1986; Archibald and Melton 1987; King et al. 1987; Yamaguchi et al. 2003; Mintz-Oron et al. 2008). In contrast, other authors have used the strictly epidermal definition of the exocarp on the basis of either histological observations (King 1938; Bain and Robertson 1951) or a histogenic approach that treats the exocarp as the part of the fruit derived from the outer epidermis of the pollinated carpel (Bobrov et al. 2005). In this case, the subepidermal layers are interpreted as being a part of the outer mesocarp or as a transitionary zone (King 1938; Bain and Robertson 1951; Roth 1977; Bobrov et al. 2005). Similarly, even when the exocarp is considered to be multiseriate, different interpretations of the number of participating subepidermal layers can be made. For example, in the sweet cherry fruit the number of subepidermal layers included in the exocarp varies between three to four (Demirsoy and Demirsoy 2004) and two to eight (Sekse 1995). Similar contradictions have been found with other (nondrupe) fleshy fruits, such as the two (Homutová and Blazek 2006) to 12 (Simons et al. 1980) subepidermal layers reported for the apple. In fleshy fruits, except for a tendency toward a relatively smaller cell size, the external fruit cells are often quite similar in appearance to those of the rest of the fruit fleshy tissue (Roth 1977), so definitions that are principally based on subjective observations are likely to vary. Modern image analysis tools for cell measurement, however, provide a means to precisely examine cell dimensions and number and could contribute valuable information about cellular patterns in this region.

Potential fruit size is genetically determined and is a desirable character in the selection and breeding of commercial fruit crops. Cell division and expansion are the principle cel- 


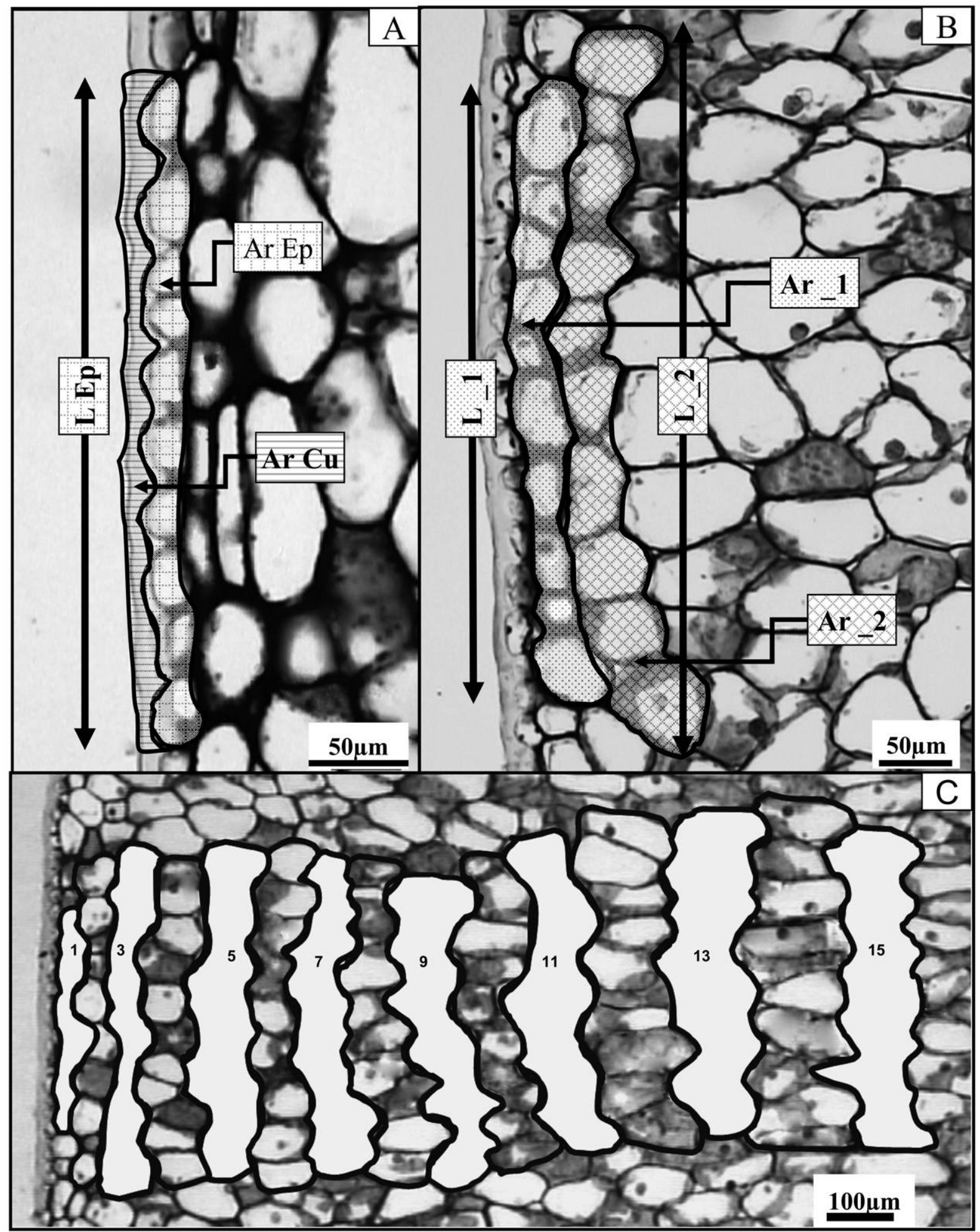

Fig. 1 Micrographs of the olive fruit exterior cells in transverse section showing the measurements that were made. The combined cell area $(\mathrm{Ar})$ and length $(\mathrm{L})$ of groups of 10 cells in tangential layers were determined for the epidermis (Ep), cuticle $(\mathrm{Cu})$, and 20 centripetally successive subtending cell layers (numbered consecutively toward the fruit interior). Those values were used to calculate mean cell area, tangential cell width, radial cell width, and cuticle thickness as described in the text. $A$, Measurements of the epidermis. $B$, Measurements of the first two subepidermal layers (indicated by_1 and_2). C, External zone of the fruit showing 10-cell groups for the first 15 layers. Each group of 10 cells is outlined; the cells of even-numbered layers are shown and those of the odd-numbered layers are covered. 


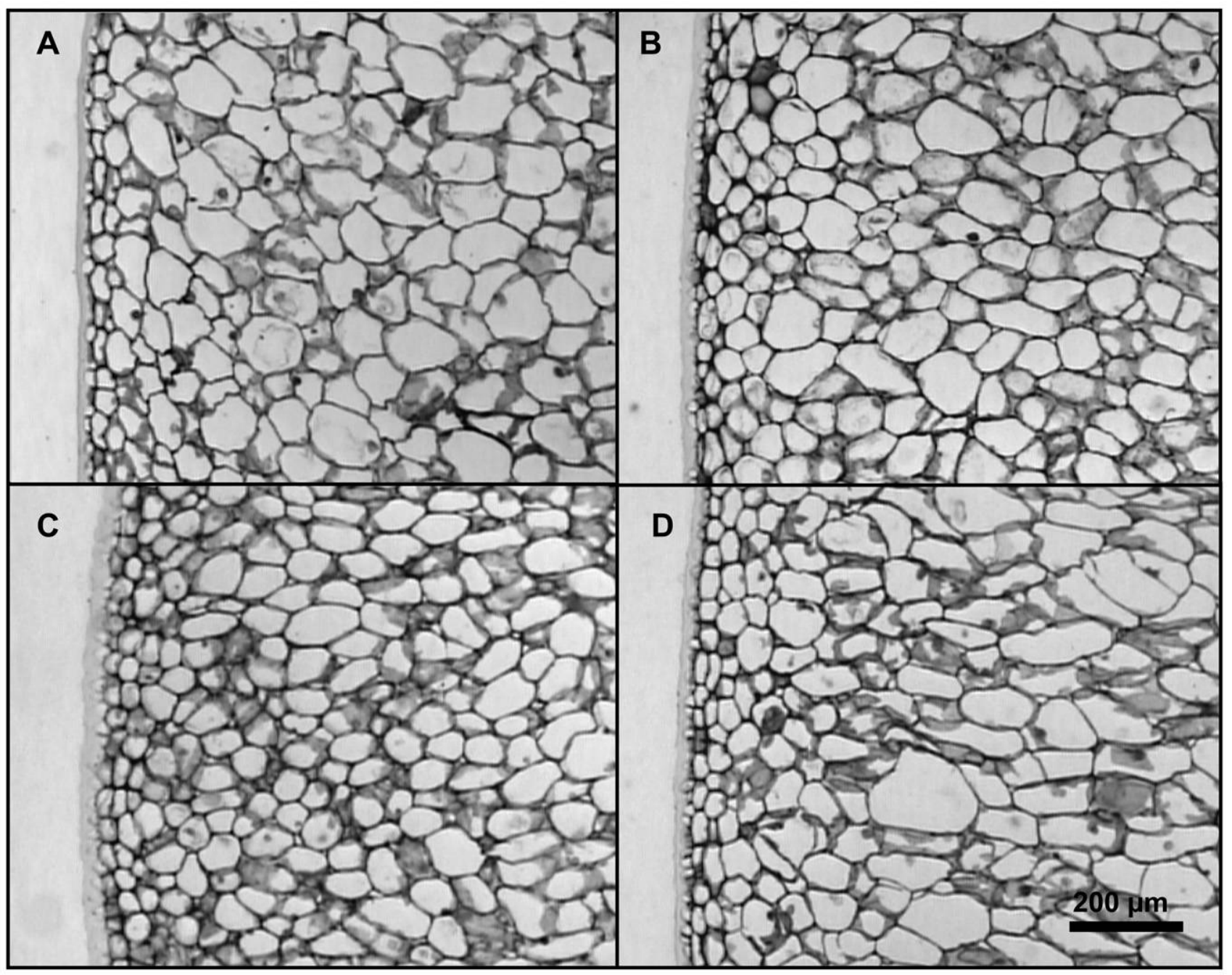

Fig. 2 Micrographs of the external fruit region the four studied olive cultivars, presented in decreasing order of fruit size. A, 'Manzanilla'; $B$, 'Hojiblanca'; $C$, 'Picual'; $D$, 'Arbequina.'

lular processes that produce the final size of fleshy fruits (Gillaspy et al. 1993). Comparative studies attribute cultivar fruit size variation to cell number (Scorza et al. 1991; Yamaguchi et al. 2004; Olmstead et al. 2007; Quilot and Génard 2008; Hammami et al. 2011) or both cell number and size when wild genotypes are included in the comparison (Yamaguchi et al. 2002; Harada et al. 2005). However, although exocarp cell activity is considered to be a relevant component of fruit development (Gillaspy et al. 1993; Lemaire-Chamley et al. 2005; Fu et al. 2010), it has generally not been considered in studies of fruit growth or with respect to genetically based size differences. Size has been found to be important for the interaction of fruits with environmental factors (Lescourret et al. 2001; Zeebroeck et al. 2006; Opara 2007; Wang et al. 2009), which raises questions about whether or how the structure of the exocarp-considered the principal tissue involved in those interactions-varies in relation to fruit size. Considine and Brown (1981) used theoretical fruit growth calculations to determine that the internal forces generated by fruit expansion increase with greater fruit size, and they suggested that those forces directly influence the external fruit tissue structure.

The fruit of the olive, Olea europaea L., has a basic drupe structure that consists of an exocarp, a mesocarp, and an endocarp; differing interpretations exist concerning the exocarp cell layers (King 1938; Lavee 1986; Mulas 1994). Olive cultivars present a wide range of fruit sizes (Del Rio and Caballero 2008), and cultivar fruit size has been indicated in terms of susceptibility to external biotic (Wang et al. 2009) and abiotic (Ferguson et al. 2010) factors. These features make the olive fruit a good model candidate for exploring exocarp structural characteristics and their relation to fruit size, as well as identifying the potential horticultural significance of this tissue.

In this study, using image analysis and statistical tools, we explore the variability of cell dimensions and number among the most external fruit cell layers and in relation to cultivar fruit size. Our results indicate important morphogenetic dif- 
Table 1

Epidermal Cell and Cuticle Parameters and Their Correlation with Transverse Fruit Diameter for the Different Olive Cultivars

\begin{tabular}{|c|c|c|c|c|c|c|}
\hline \multirow[b]{2}{*}{ Cultivar } & \multicolumn{2}{|c|}{ Cuticle } & \multicolumn{3}{|c|}{ Epidermal cell size $^{\mathrm{a}}$} & \multirow[b]{2}{*}{ Epidermal cell number } \\
\hline & Thickness $(\mu \mathrm{m})$ & Area/cell $\left(\mu \mathrm{m}^{2}\right)$ & Radial width $(\mu \mathrm{m})$ & Tangential width $(\mu \mathrm{m})$ & Area $\left(\mu \mathrm{m}^{2}\right)$ & \\
\hline 'Manzanilla' & $10.12^{\mathrm{C}}$ & $291.40^{\mathrm{B}}$ & $15.61^{\mathrm{C}}$ & $29.60^{\mathrm{A}}$ & $462.86^{\mathrm{B}}$ & $2216.7^{\mathrm{A}}$ \\
\hline 'Hojiblanca' & $13.46^{\mathrm{B}}$ & $379.89^{\mathrm{A}}$ & $17.11^{\mathrm{B}}$ & $27.51^{\mathrm{B}}$ & $470.90^{\mathrm{AB}}$ & $2130.4^{\mathrm{A}}$ \\
\hline 'Picual' & $14.50^{\mathrm{A}}$ & $362.04^{\mathrm{A}}$ & $20.34^{\mathrm{A}}$ & $24.99^{\mathrm{C}}$ & $508.94^{\mathrm{A}}$ & $2126.1^{\mathrm{A}}$ \\
\hline 'Arbequina' & $13.23^{\mathrm{B}}$ & $279.68^{\mathrm{B}}$ & $19.12^{\mathrm{A}}$ & $21.33^{\mathrm{D}}$ & $409.11^{\mathrm{C}}$ & $2134.5^{\mathrm{A}}$ \\
\hline Correlation with fruit size & $-.59 *$ & $.22^{\dagger}$ & $-.58 *$ & $.96 * * *$ & $.52 *$ & $.07^{\dagger}$ \\
\hline
\end{tabular}

Note. Cultivars are listed in descending fruit size order. Epidermal cell number is the total number of epidermal cells in the fruit median transverse section. Correlation with fruit size is determined by the Pearson coefficient. Different uppercase superscript letters indicate significant differences within columns at $P<0.05$ (by least significant difference test).

${ }^{a}$ Excluding cuticle.

$* P<0.05$.

$* P<0.01$.

$* * P<0.001$.

${ }^{\dagger}$ Not significant.

ferences in the epidermis-particularly, in the subepidermal tissues-that suggest a new characterization of the cellular layers. Furthermore, the comparison of fruits from cultivars of different fruit size provides useful insight into overall fruit developmental processes and, on a practical level, fruit susceptibility to environmental impact. To our knowledge, this is the first evaluation of its kind conducted on a fleshy fruit.

\section{Material and Methods}

\section{Plants and Experiment Design}

We evaluated fruits of the following four olive tree (Olea europaea L.) cultivars with a range of mature fruit sizes (in order from large to small): 'Manzanilla de Sevilla,' 'Hojiblanca,' 'Picual,' and 'Arbequina' (Barranco 2004). The range of fruit sizes represents a fruit central transverse area of $150-350 \mathrm{~mm}^{2}$ and an area of $140-280 \mathrm{~mm}^{2}$ or $20 \times 10^{3}-40 \times 10^{3}$ cells of fleshy (mesocarp and exocarp) tissue (Hammami et al 2011). The fruits we examined were collected from trees that were 20 years old and planted at a standard density of 270 trees $\mathrm{ha}^{-1}$ at the experimental farm Alameda del Obispo, of the Andalusian Institute for Research and Training in Agriculture, Food, and Fisheries in Cordoba, Spain. Four trees per cultivar were randomly distributed in each of four rows. Trees of each cultivar had similar, moderately high crop loads and were grown with irrigation under standardized cultivation conditions.

\section{Fruit Preparation and Measurement}

At fruit maturity, which was determined by the onset of color change, five fruits per tree were sampled around the tree circumference and fixed in formalin-acetic acid $(60 \%$ ethanol, $2: 1: 17 \mathrm{v} / \mathrm{v})$. Structural observations and measurements were performed on transverse sections of the mesocarp at the point of widest fruit diameter, which were obtained following rehydration and pitting (removal of the stony endocarp) of the fixed fruits. Complete $5-\mathrm{mm}$ mesocarp slices were processed according to standard paraffin procedures, sectioned at $10-12 \mu \mathrm{m}$, and stained with toluidine blue $\mathrm{O}$ be- fore paraffin removal (Sakai 1973). Although these methods are known to produce some tissue shrinkage (Ruzin 1999), we considered the procedures to be appropriate for the cultivar comparisons because the material was similar in nature and because previous tests indicated that the shrinkage effect is consistent for olive fruits of different size, development, and water status (Gucci et al. 2009). Also, because of the three-dimensional structure of the fruit and its cells, and because of cell packing, the cell size measurements in transverse section represent the contribution per cell to that section, rather than the central or maximum transverse size of each cell (Legland et al. 2010). These limitations, however, apply to all of the measurements and should not invalidate the comparisons either among cell layers or among cultivars.

Quantitative observations of the external fruit tissue were made from the prepared transverse sections with the use of an image analysis system (Moticam 2500 and Motic Images Plus 2.0 ML, Motic China Group, Xiamen) connected to an ocular microscope (Motic BA 310, Motic China Group). Measurements were performed in three different locations around the transverse fruit section. In each location, we measured the combined area and length of 10 cells forming a tangential layer, and then we measured area and length separately for the cuticle covering the 10-cell group of epidermal cells in the epidermis and the 20 successive subtending cell layers (fig. 1). In each layer, average cell area and average tangential cell width were calculated by dividing by 10 the area and the tangential length, respectively, of the measured cell groups. Likewise, cuticle thickness was calculated by dividing the combined cuticle area by the combined tangential length of the 10 epidermal cells we measured. The mean radial cell width was determined in a similar fashion as the total area of each 10-cell layer divided by the (tangential) length; in the case of the epidermis, the cuticle was not included in the measurements.

Fruit equatorial transverse diameter was measured before pit removal. Fruit diameter and the radial widths of the measured cell layers were used to calculate the circumference of each layer, which was then used to determine the total number of cells composing each layer in the fruit transverse section. The total cell number exterior to the endocarp (pit) was 

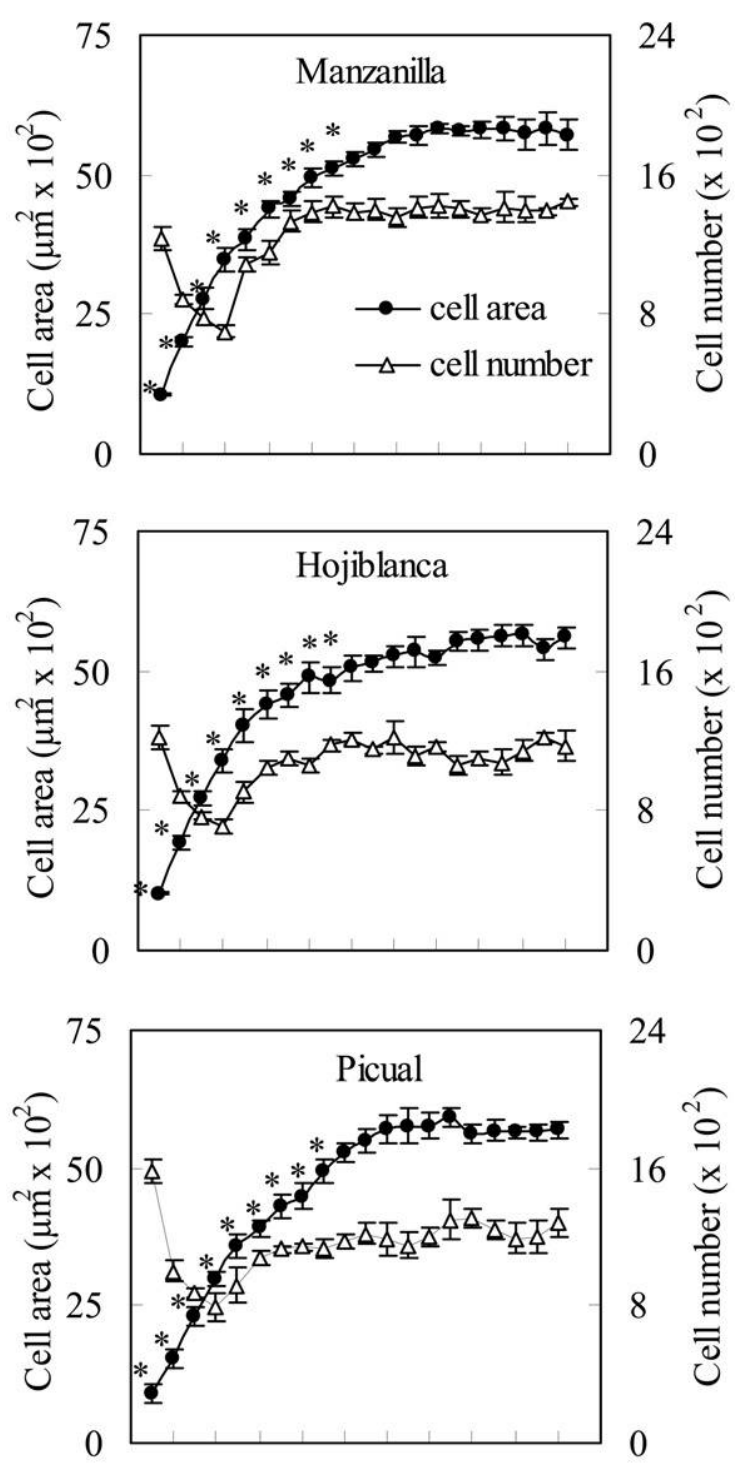

24
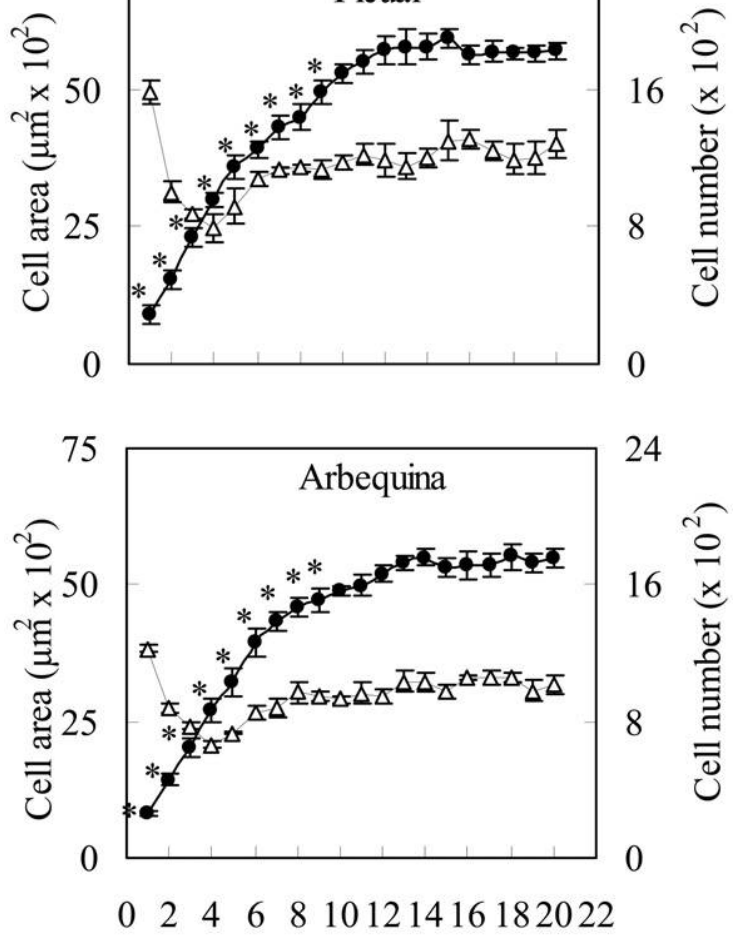

Centripetal cell layer order

Fig. 3 Cell area (circles) and cell number (triangles) for each of the 20 first successive subepidermal cell layers in four olive cultivars. Cell number is the total number of cells in each cell layer in the fruit transverse section. Vertical bars represent the standard error of 20 determined in transverse section according to the methods of Hammami et al. (2011). When analyzing and discussing fruit tissue size, we used the term "fruit flesh" to describe all fruit tissue exterior to the endocarp, in order to avoid using the terms "mesocarp" and "exocarp" before we made our interpretations.

\section{Data Analysis}

The experimental design of this study was completely randomized, with four replications (trees) per cultivar and five fruits per replication. For each fruit, we used the means of the values of the three measurement zones. All analysis was performed using Statistix 8 (Analytical Software, Tallahassee, FL). A one-factor ANOVA was performed to test the influence of cultivar on the cuticle and epidermal cell dimensions, and means were compared by using the least significant difference test at $P<0.05$. Before performing ANOVA, data normality and variance homogeneity assumptions were tested using the Shapiro-Wilk and Bartlett tests, respectively.

The 20 successive tangential cell layers were identified by an order number $(N)$ from 1 to 20 , starting with the first subepidermal layer and progressing centripetally. Cell size and number values were expressed as means plus or minus the standard error of the mean $( \pm \mathrm{SE})$. The Pearson coefficient correlation procedure was used to determine the relationship between fruit size and different structural parameters.

The mean cell size of each layer was contrasted with that of the previous (more external) and succeeding layers and with the maximum cell area observed among the 20 evaluated cell layers, using the comparison with largest value statistical procedure. The comparison with smallest value statistical procedure was used to compare the relative increase in cell area between each two successive layers. Linear regression analysis was used to test the relationships of the cell measurements with cell layer order and fruit size. To perform these analyses, data normality was confirmed with the Shapiro-Wilk test.

\section{Results}

\section{Visual Observation}

The epidermal cells, which were observed in transverse section, are small, wider tangentially than radially, and covered by a continuous and conspicuous cuticle (fig. 2). All cells interior to the epidermis are parenchymatic in nature, and their cell walls are generally similar in appearance following toluidine blue staining (Sakai 1973). In transverse section, the most external cells are isodiametric in shape and smaller than the more internal cells, which also tend to elongate in the radial dimension. Although different cell sizes and shapes exist, no clear visual distinction indicates different tissue or cell types.

replicates (five fruits per tree and four trees per cultivar). Asterisks indicate significant difference with the largest cell area in the 20 layers as determined by the comparison with largest value statistical procedure $(P<0.05)$. 

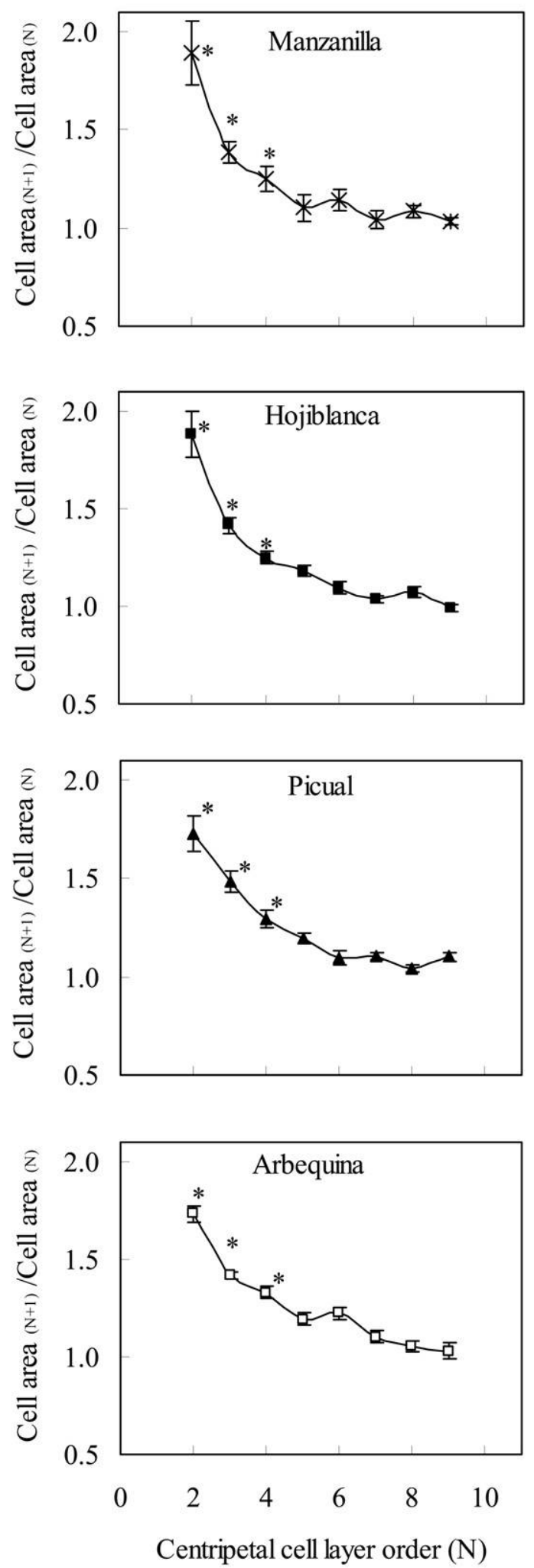

Fig. 4 Layer-by-layer cell size gradient shown as relative increase of cell area between each two successive cell layers, calculated as cell $\operatorname{area}_{(N)}$ divided by cell area $a_{(N+1)}$ (where $N$ indicates cell layer order) for each of the nine first successive subepidermal cell layers in four

\section{Measurements of the Epidermis}

Epidermal cell number was similar for all cultivars, but a definite cultivar influence was observed in all other epidermal parameters (table 1). The cultivars 'Picual' and 'Hojiblanca' presented thick cuticles and a high cuticle area per cell, 'Arbequina' had a thick cuticle but a low cuticle area per cell, and 'Manzanilla' had both a thin cuticle and a low cuticle area per cell. The three cell size parameters-radial width, tangential width, and area-differed substantially among cultivars, but tangential width was always greater than radial width. Significant correlations were found between cultivar fruit diameter and some of the epidermal dimensions (table 1). Thus, thinner cuticles were found with greater fruit size, but the amount (area) of cuticle per epidermal cell was not affected. Epidermal cell area and tangential cell width increased linearly with fruit size, while radial cell width was reduced.

\section{Cell Dimensions in Successive Subepidermal Layers}

The cell areas in the first 20 subepidermal cell layers revealed consistent patterns in all cultivars (fig. 3). Cell area increased centripetally toward the fruit interior, forming a gradient of increasing cell size between successive cell layers. In the first nine layers, cell size values were significantly lower than the highest value found in the 20 evaluated layers of each cultivar. In contrast, in the subsequent layers, cell size values were statistically similar to the highest value. In all cultivars, the overall increase in cell size between the first and the ninth layer was substantial, ranging from 5.4 ('Manzanilla') to 6.7 times ('Arquebina').

For the first 20 cell layers, total cell number per layer in the complete fruit transverse section was similar in pattern among the cultivars, although it differed somewhat in value (fig. 3). Centripetally, starting with the first subepidermal layer, cell number decreased rapidly for layers $1-4$. From the fifth layer, cell number began to increase and then became constant by the ninth layer. For the following internal layers, both cell size and cell number remained unchanged. On the basis of these results and those for cell size (reported above), our subsequent analysis focused principally on the first nine subepidermal layers.

The layer-by-layer gradient in cell area was calculated as cell $\operatorname{area} a_{(N+1)}$ divided by cell $\operatorname{area}_{(N)}$ (where $N$ is the cell layer order) and statistically compared with the lowest-observed gradient value (fig. 4). This analysis indicated that the gradient in all cultivars was significantly greater for layers 1-4 and decreased rapidly toward the fruit interior.

Cell tangential and radial width increased linearly in relation to centripetal cell layer order in layers 1-4 (fig. 5). In the following five layers (layers 5-9), the relationship changed: radial cell width continued to increase linearly, although to a lesser degree than at first, and in contrast, tangential cell width became uniform. In general, the linear regressions (fig. 4) were stronger for radial than tangential growth.

olive cultivars. Cell areas are presented in figure 3. Vertical bars represent the standard error of 20 replicates (five fruits per tree and four trees per cultivar). Asterisks indicate significant difference with the smallest observed value as determined by the comparison with smallest value statistical procedure $(P<0.05)$. 

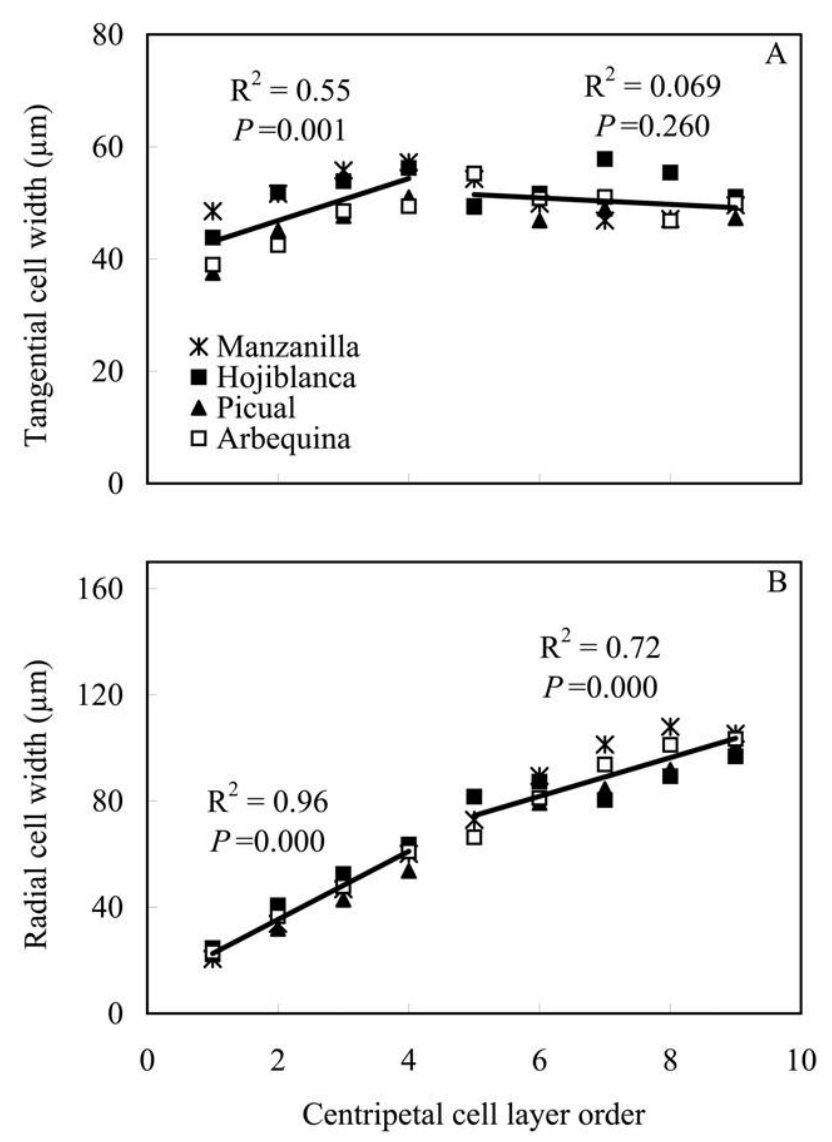

Fig. 5 Linear regressions of the tangential $(A)$ and radial $(B)$ cell widths for subepidermal layers 1-4 and 5-9 (cell layers ordered centripetally). Correlation is significant when $P<0.05$. Each point represents the average value per cultivar.

\section{Cell Dimensions in Relation to Fruit Size}

The relationships between cell parameters and cultivar fruit size varied according to cell layer order, with very different results for layers 1-4 than for layers 5-9 (table 2). Linear correlations were found between fruit diameter and both tan- gential cell width and cell area for layers $1-4$, whereas these relationships were absent for layers 5-9. This correlation was higher for tangential cell width than for cell area, but in both cases it decreased with centripetal layer order. In direct contrast to cell area and tangential width, cell number per layer increased with cultivar fruit size only in layers 5-9. Radial cell width, however, was not related to cultivar fruit size in any of the layers. Thus, overall, fruit size was associated with cell size-specifically, in the tangential sense-in layers 1-4, whereas in layers 5-9 it was associated with cell number.

Transverse fruit diameter was significantly different among all cultivars (table 3 ). The percentages of fruit flesh cell number and area pertaining to layers 1-4 and layers 5-9 decreased significantly in relation to cultivar fruit size (table 3 ). These two layer groups together contributed $28 \%$ of the total cell number but occupied only $12 \%$ of the total fruit flesh area. Neither the combined radial width of layers 1-4 (fig. $6 B$ ) nor that of layers 5-9 (fig. 6C) was correlated with fruit size, but a significant inverse correlation was found between fruit size and epidermis width (fig. 6A).

\section{Discussion}

\section{Cellular Dimensions and Numbers in the External Fruit Zone}

The olive epidermis revealed a similar general structure to that of other drupe fruits (Roth 1977). That is, the epidermal cells observed in transverse section are small in size $(\sim 450$ $\mu \mathrm{m}^{2}$ ), covered by a continuous cuticle, and wider tangentially than radially. The cuticle of olive fruits, however, is much more developed than those of other commercial drupes with larger fruits. For example, cuticle thickness is between 3 and $4 \mu \mathrm{m}$ in plum fruits (Sterling 1953) and between 2 and $5 \mu \mathrm{m}$ in nectarine fruits (King et al. 1987), whereas it is 10$14 \mu \mathrm{m}$ in the olive fruits we measured (table 1). Furthermore, the cuticle occupies a greater proportion of the epidermis, $\sim 40 \%$, as compared with $\sim 20 \%$ for sweet cherry fruit (Demirsoy and Demirsoy 2004), a drupe of similar size. These results suggest an important role of the cuticle in olive fruit biology.

Smaller cell size in the zone directly beneath the epidermis than in the rest of the mesocarp has been reported for differ-

Table 2

Correlations (Pearson Coefficient) between Cell Measurements and Cultivar Fruit Size, Determined for Each of the First Nine Subepidermal Layers

\begin{tabular}{lccccccccc}
\hline & \multicolumn{8}{c}{ Centripetal cell layer order } \\
\cline { 2 - 9 } Cell measurement & 1 & 2 & 3 & 4 & 5 & 6 & 7 & 8 & 9 \\
\hline Cell area & $.57^{*}$ & $.58^{*}$ & $.56^{*}$ & $.54^{*}$ & $.39^{\dagger}$ & $.40^{\dagger}$ & $.31^{\dagger}$ & $.41^{\dagger}$ & $.21^{\dagger}$ \\
Tangential cell width & $.75^{* *}$ & $.83^{* * *}$ & $.77^{* * *}$ & $.55^{*}$ & $-.04^{\dagger}$ & $.14^{\dagger}$ & $.07^{\dagger}$ & $.31^{\dagger}$ & $.24^{\dagger}$ \\
Radial cell width & $-.23^{\dagger}$ & $.09^{\dagger}$ & $.27^{\dagger}$ & $.26^{\dagger}$ & $.38^{\dagger}$ & $.25^{\dagger}$ & $.05^{\dagger}$ & $.17^{\dagger}$ & $-.02^{\dagger}$ \\
Cell number & $-.08^{\dagger}$ & $-.05^{\dagger}$ & $.38^{\dagger}$ & $.43^{\dagger}$ & $.78^{* * *}$ & $.75^{* * *}$ & $.76^{* * *}$ & $.66^{* *}$ & $.87^{* * *}$ \\
\hline
\end{tabular}

Note. Cell number is the total number of cells in the corresponding cell layer in the fruit transverse section.

* $P<0.05$.

$* P<0.01$.

$* * P<0.001$.

${ }^{\dagger}$ Not significant. 
Table 3

Fruit Size and Proportions of Fruit Flesh Area and Fruit Flesh Cell Number Pertaining to the First Four (1-4) and the Next Five (5-9) Subepidermal Cell Layers for the Different Olive Cultivars

\begin{tabular}{lcccccc}
\hline & & \multicolumn{2}{c}{ Layers $1-4$} & & \multicolumn{2}{c}{ Layers 5-9 } \\
\cline { 3 - 4 } Cultivar & Fruit diameter $(\mathrm{mm})$ & $\begin{array}{c}\text { Fruit flesh } \\
\text { area }\end{array}$ & $\begin{array}{c}\text { Fruit flesh } \\
\text { cell no. }\end{array}$ & & $\begin{array}{c}\text { Fruit flesh } \\
\text { area }\end{array}$ & $\begin{array}{c}\text { Fruit flesh } \\
\text { cell no. }\end{array}$ \\
\hline 'Manzanilla' & $20.22^{\mathrm{A}}$ & $3.37^{\mathrm{C}}$ & $10.17^{\mathrm{C}}$ & & $6.82^{\mathrm{C}}$ & $12.88^{\mathrm{C}}$ \\
'Hojiblanca' & $18.66^{\mathrm{B}}$ & $3.98^{\mathrm{BC}}$ & $10.12^{\mathrm{C}}$ & & $7.26^{\mathrm{C}}$ & $13.95^{\mathrm{C}}$ \\
'Picual' & $16.94^{\mathrm{C}}$ & $4.40^{\mathrm{B}}$ & $13.70^{\mathrm{B}}$ & & $8.70^{\mathrm{B}}$ & $15.51^{\mathrm{B}}$ \\
'Arbequina' & $14.48^{\mathrm{D}}$ & $5.59^{\mathrm{A}}$ & $16.78^{\mathrm{A}}$ & & $10.21^{\mathrm{A}}$ & $18.45^{\mathrm{A}}$ \\
\hline
\end{tabular}

Note. Cultivars are listed in descending fruit size order and were compared using one-way ANOVA. The term "fruit flesh" indicates all fruit tissue exterior to the pit (explained in "Material and Methods"). Data are percentages unless otherwise indicated. Different uppercase superscript letters indicate significant differences within columns at $P<0.05$ (by least significant difference test).

ent fleshy fruits (apple: Bain and Robertson 1951; avocado: Schroeder 1953; cucumber: Marcelis and Hofman-Eijer 1993). Our measurements in olive fruits revealed not only that the subepidermal region was composed of small cells but also that cell size increased centripetally, to form a clear gradient among successive cell layers. The zone in which this gradient occurred was limited to an equal nine subepidermal layers in all genotypes, representing only $4 \%-8 \%$ of the total fruit radius. Because cell size is the combined result of cell division and expansion (Green 1976; Evans 2000), the observed differences in cell size suggest differences in the activities of these two cellular processes.

Observations of fleshy fruit cell form have usually reported elongation in the tangential direction for the cells directly subjacent to the epidermis, while elongation in the radial direction is more typical for the internal fruit mesocarp cells (King 1938; Sterling 1953; Skene 1966; Archibald and Melton 1987), apparently in relation to physical pressures in fruit expansion. However, the tangential and radial changes in cell width that we found across the most external nine subepidermal layers (fig. 5) suggest a dimensional complexity of both cell division and expansion in those layers. Thus, the cell size increases we observed among layers 1-4 resulted from cell expansion in both tangential and radial directions, whereas those we observed in layers 5-9 were principally produced by radial expansion.

Differences among the first nine subepidermal layers were not limited to cell dimensions but were also found for fruit cell number per layer. Three successive patterns-a cell number that was centripetally decreasing, then increasing, then constant-occurred radially across the nine cell layers (fig. 3 ). High cell division activity has frequently been attributed to the outer zone of fleshy fruit tissue by both anticlinal divisions, which determine the cell number per layer, and periclinal divisions, which determine the number of layers (Skene 1966; Considine and Knox 1981; King et al. 1987). The high proportion $(28 \%)$ of total fruit flesh cell number pertaining to the first nine subepidermal layers (table 3 ) appears to indicate high cell division, whereas the cell number differences we observed among layers reflect differences in anticlinal cell division. In the olive fruit, overall cell number initially increases rapidly and then continues throughout fruit development at a much lower rate (Hammami et al. 2011). However, relative cell division activity in the different fruit zones has important implications for cell aging and fruit expansion, as well as for interpreting the observed differences among layers, and would be of interest to examine in further studies.

\section{Relationships of Fruit Size to Epidermal and Subepidermal Cell Patterns}

Cell size in the epidermis and in subepidermal layers 1-4 increased linearly with cultivar fruit size, but cell number did not (table 2). In contrast, cultivar fruit size variability is generally due to mesocarp cell number rather than cell size in olives (Hammami et al. 2011) and other drupes (Scorza et al. 1991; Yamaguchi et al. 2004; Olmstead et al. 2007; Quilot and Génard 2008), and this pattern was observed in layers 5-9. This contrasting behavior indicates a morphogenetic difference between layers 1-4, which behave in a similar manner to the epidermis, and layers 5-9, which behave in the same manner as the mesocarp.

Similar to cell area, tangential width of the epidermal cells increased linearly with fruit size, but greater fruit size was associated with a thinner epidermis because of a thinner cuticle and reduced radial cell width (table 1). Thus, increased fruit size involves a reduction in the radial dimension and an increase in the tangential dimension, suggesting thinning due to physical stretching of the epidermis. This mode of action is supported by Considine and Brown (1981), who used calculations to demonstrate that with greater fruit size, internal fruit expansion forces increase, modifying cell geometry as a consequence of tangentially oriented mechanical stress along the fruit surface. Epidermis thickness is considered to protect fruits against biotic and abiotic external factors (Manandhar et al. 1995; Romig 1995; Kubo and Hiratsuka 1999; Hong et al. 2008; Ghafir et al. 2009). In this sense, the high susceptibility to mechanical damage of 'Manzanilla de Sevilla' fruits (Jiménez et al. 2012) could probably be due in part to this cultivar's thinner epidermis providing less protection.

The decreasing proportion of area occupied by layers 1-4 in increasingly larger fruit (table 3), as well as cell size differences in that region among cultivars (table 2), could impact interaction with external factors and, consequently, fruit quality. Indeed, cell dimensions in the external fruit zone appear to influence fruit quality and susceptibility to physical damage in a number of fruit crops (sweet cherry: Yamaguchi 

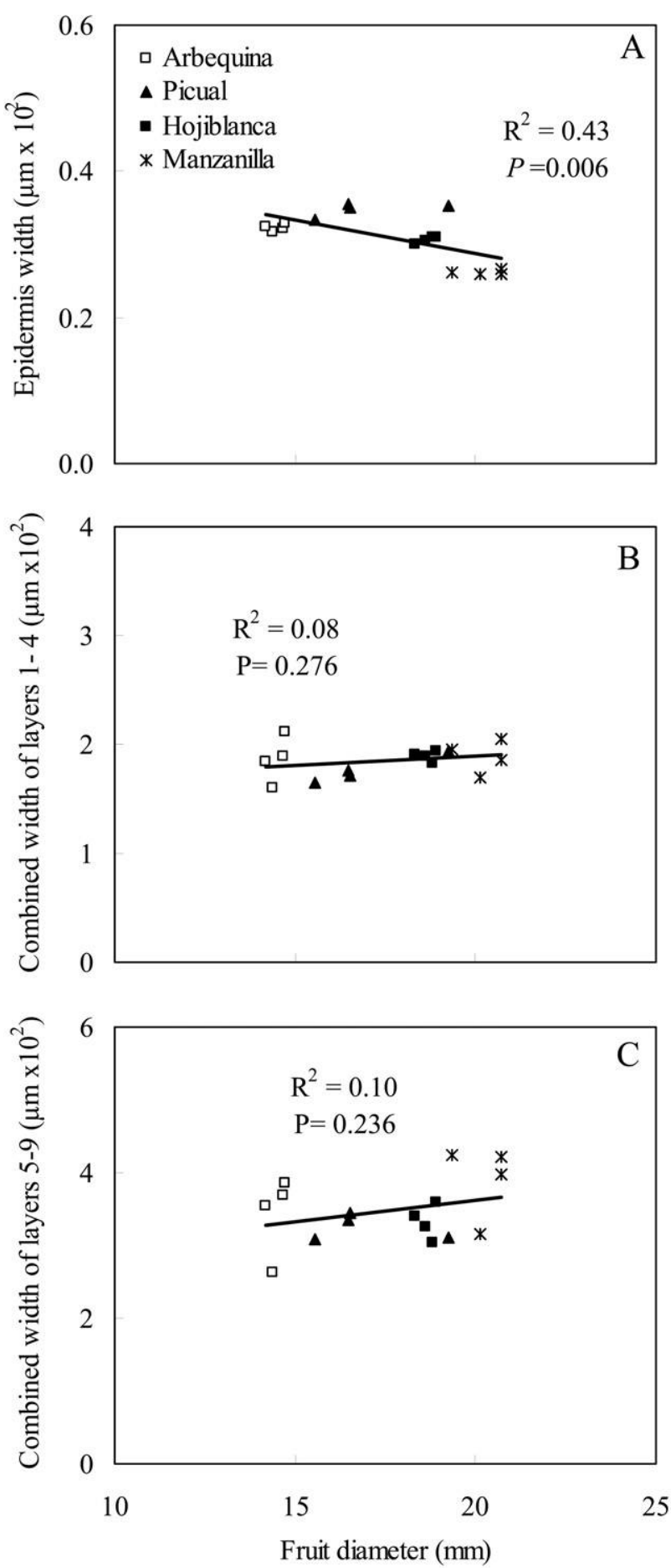

Fig. 6 Linear regressions of transverse fruit diameter with the epidermis $(A)$ and widths of subepidermal layers 1-4 (B) and 5-9 (C). Each point represents the average for five fruits per tree. Correlation is significant when $P<0.05$.

et al. 2003; pear: Hong et al. 2008; apple: Ouattara et al. 2011), but further experimental testing is necessary for confirmation and general applicability of that proposition.

\section{Tissue Organization in the External Fruit Region}

In fleshy fruits, subepidermal tissue that differs from the mesocarp in size and form and is frequently considered a hypodermis has mainly been identified on the basis of histogenic criteria (Roth 1977). Our quantitative or morphometric approach demonstrates the existence of definitive differences in cell size and number across the most external region of the fruit, which can provide valuable information regarding cellular behavior and exocarp tissue composition. For the four olive cultivars and all of the cell layers we evaluated (epidermis and 20 subepidermal layers), cellular patterns changed centripetally at two consistent positions along the fruit transverse radius, thus defining the following three different regions: (1) the epidermis plus the first four immediately subepidermal layers (layers 1-4), (2) the five centripetally internal layers (layers 5-9), and (3) the subsequent 11 internal cell layers (layers 10-20).

A number of characteristics indicate that the most internal layers we studied, layers 10-20, are part of and form a continuum with the rest of the mesocarp tissue. First, cell size is constant among all 11 cell layers and larger than in the first nine subepidermal layers (fig. 3), in agreement with the high cell expansion activity characterizing mesocarp cells when compared with those located near the fruit exterior (LemaireChamley et al. 2005; Schlosser et al. 2008; Fu et al. 2010). Second, the cell area values we calculated for these internal 11 cell layers were very similar to those found for cells throughout the mesocarp in a previous study of the same olive cultivars (Hammami et al. 2011). Finally, when a multiseriate exocarp has been described for olive fruits, a maximum of four subepidermal layers have been reported (Lavee 1986; Mulas 1994), whereas no further internal layers have ever been attributed to any tissue other than mesocarp.

The region composed of layers 5-9, although displaying a cell size gradient, was much more similar to the mesocarp than to the external layers $1-4$. In fact, the main difference observed between those five layers and the mesocarp in general was cell size, but cells of both of these zones behave in a similar manner in relation to cultivar fruit size and exhibit a similar tendency toward cell radial elongation. Layers 5-9 could be considered to compose an outer mesocarp, using the name given by King (1938) for the region of smaller cells he observed in the outer zone of olive fruit flesh.

The first four subepidermal layers (1-4) were unmistakably distinct. In those layers, the cell size gradient was produced by both radially and tangentially oriented cell expansion, in contrast to only radial cell expansion in the other layers. In the grape berry, the exocarp and mesocarp tissues differ in orientation of cell expansion as well as in the timing of this expansion (Huang and Huang 2001; Schlosser et al. 2008). Cell size in these layers was clearly smaller than in the mesocarp cells, which supports cell size being an important criterion for identifying a hypodermis (Roth 1977). As indicated above, in layers 1-4, cell size but not cell number was associated with genetically based fruit size differences (table 2 ), in direct contrast with the pattern observed for more internal layers and the general behavior of fruit mesocarp tissue (Scorza et al. 1991; Yamaguchi et al. 2004; Olmstead et al. 2007; Quilot and Génard 2008; Hammami et al. 


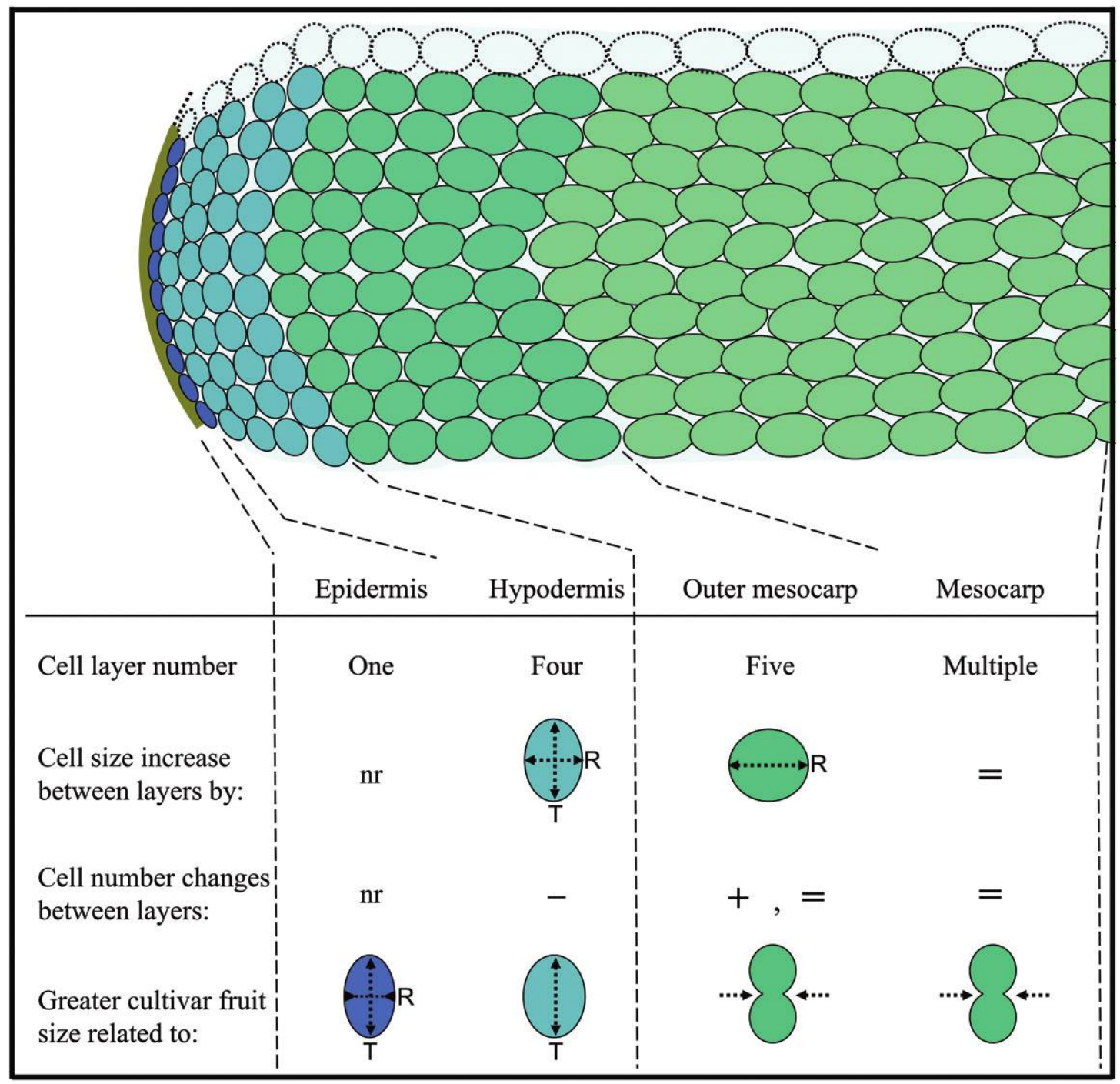

Fig. 7 Diagram of observed cellular characteristics and organization in the external region of the olive fruit. Successive cell layers are shown from the epidermis (left) and proceeding centripetally within the fruit, and their observed characteristics (summarized at bottom of figure). Letters $\mathrm{T}$ (tangential) and $\mathrm{R}$ (radial) and arrows indicate orientation of cell activities. Arrows inside a cell show the orientation of size change (cell expansion or shape modification); external arrows show cell division, with orientation only for the outer mesocarp (not evaluated in the other mesocarp layers). Symbols for changes are defined as follows: plus sign, increase; minus sign, decrease; equals sign, no change; nr, not relevant. Measurements were based on groups of 10 cells per layer, as explained in the text.

2011). The greater tangential cell expansion we observed in layers 1-4 has also been noted in grape berries by Schlosser et al. (2008), who found that internal expansion produced pressure that forced the hypodermal cells to expand tangentially. Tissue expansion forces of this nature are consistent with the high correlation observed between fruit size and tangential cell width in layers 1-4. All of these distinctive cellular characteristics of layers 1-4 indicate that they behave as an independent tissue that is different from the mesocarp.

The epidermal cells were similar to those of subepidermal layers 1-4 in their tendency to elongate tangentially. They were also similar in that cultivar fruit size variability was related to cell size rather than cell number. In other fleshy fruits, Considine and Knox (1981) found similarities in epidermal and hypodermal cellular development during fruit growth, which they interpreted as suggesting a common nature or origin of the epidermis and hypodermis; this assessment strengthens the interpretation of layers 1-4 having a hypodermal nature in olive fruit. All of these results provide strong morphometric evidence of a consistent external zone in the olive fruit, independent of cultivar and fruit size, that is composed of the epidermis plus four hypodermal layers. This zone might be considered to be a multiseriate exocarp. Further testing of this hypothesis could focus on examining cell wall thickness and cell composition, which has been found to differ between the grape berry exocarp and mesocarp (Huang and Huang 2001; Schlosser et al. 2008). It 
would also be of interest to evaluate more olive genotypes, as well as other species of drupes.

The results obtained in this study, and the tissue organization they suggest, are summarized schematically in figure 7 . Successively increasing cell size was found in the first nine subepidermal cell layers in all cultivars. These nine layers are divided into two parts-the first 1-4 layers and the following 5-9 layers-that displayed consistent differences. Cell size and number distinguish the first zone as a hypodermis and suggest the possibility of a multiseriate exocarp formed by the hypodermis plus the epidermis. The number of subepidermal layers forming the hypodermis in olive fruit-four-was consistent among cultivars. In the epidermis and subepidermal layers, genetically based fruit size difference correlated with cell size but not cell number, in contrast to current and previous observations in the mesocarp. The five cell layers immediately internal to the hypodermis, which are composed of smaller cells than the mesocarp but are otherwise similar in behavior, might be considered as outer mesocarp. This morphometric analytical approach provides new insights regarding tissue organization in the mature olive fruit and warrants application to the study of fruit structure during the course of development and the study of other fleshy fruit species.

\section{Acknowledgments}

We wish to thank Trinidad Manrique and Ester GarcíaCuevas for excellent technical assistance in fruit sampling and histological preparation. The study was funded by the Ministry of Science and Innovation of Spain and European Research and Development Funds (grant AGL2009-07248).

\section{Literature Cited}

$\rightarrow$ Archibald RD, LD Melton 1987 The anatomy of the fleshy pericarp of maturing Moorpark apricots, Prunus armeniaca. N Z J Bot 25: 181-184.

Bain MJ, RN Robertson 1951 The physiology of growth in apple fruits. I. Cell size, cell number, and fruit development. Aust J Biol Sci 4:75-91.

$\rightarrow$ Bargel H, C Neinhuis 2005 Tomato (Lycopersicon esculentum Mill.) fruit growth and ripening as related to the biomechanical properties of fruit skin and isolated cuticle. J Exp Bot 56:1049-1060.

Barranco D 2004 Varieties and rootstock. Pages 63-92 in D Barranco, RE Fernández, L Rallo, eds. Olive cultivation. Mundi, Madrid.

$\rightarrow$ Bobrov AVFC, PK Endress, AP Melikian, MS Romanov, AN Sorokin, AP Bejerano 2005 Fruit structure of Amborella trichopoda (Amborellaceae). Bot J Linn Soc 148:265-274.

Bollard EG 1970 The physiology and nutrition of developing fruits. Pages 387-425 in AC Hulme, ed. The biochemistry of fruits and their products. Academic Press, London.

$\rightarrow$ Considine J, K Brown 1981 Physical aspects of fruit growth: theoretical analysis of distribution of surface growth forces in fruit in relation to cracking and splitting. Plant Physiol 68:371-376.

$\rightarrow$ Considine JA, RB Knox 1981 Tissue origins, cell lineages and patterns of cell division in the developing dermal system of the fruit of Vitis vinifera L. Planta 151:403-412.

$\rightarrow$ Coombe BG 1976 The development of fleshy fruits. Annu Rev Plant Physiol 27:207-228.

Del Rio C, JM Caballero 2008 Variability and classification of olive cultivars by fruit weight, flesh/stone ratio and oil percentage. Acta Hortic 791:39-44.

Demirsoy L, H Demirsoy 2004 The epidermal characteristics of fruit skin of some sweet cherry cultivars in relation to fruit cracking. Pak J Bot 36:725-731.

$\rightarrow$ Evans LS 2000 Diversity of cell lengths in terminal portions of roots: implications to cell proliferation. Environ Exp Bot 43:239-251.

Ferguson L, UA Rosa, S Castro-Garcia, SM Lee, JX Guinard, J Burns, WH Krueger, NV O'Connell, K Glozer 2010 Mechanical harvesting of California table and oil olives. Adv Hortic Sci 24:53-63.

$\rightarrow$ Fu FQ, WH Mao, K Shi, YH Zhou, JQ Yu 2010 Spatio-temporal changes in cell division, endoreduplication and expression of cell cycle-related genes in pollinated and plant growth substancestreated ovaries of cucumber. Plant Biol 12:98-107.

Ghafir SAM, SO Gadalla, BN Murajei, MF El-Nady 2009 Physiological and anatomical comparison between four different apple cultivars under cold-storage conditions. Afr J Plant Sci 3:133-138.
Gillaspy G, H David, W Gruissem 1993 Fruits: a developmental perspective. Plant Cell 5:1439-1451.

$\rightarrow$ Green PB 1976 Growth and cell pattern formation on an axis: critique of concepts, terminology, and modes of study. Bot Gaz 137: 187-202.

$\rightarrow$ Gucci R, EM Lodolini, HF Rapoport 2009 Water deficit-induced changes in mesocarp cellular processes and the relationship between mesocarp and endocarp during olive fruit development. Tree Physiol 29:1575-1585.

$\rightarrow$ Hammami SBM, T Manrique, HF Rapoport 2011 Cultivar-based fruit size in olive depends on different tissue and cellular processes throughout growth. Sci Hortic 130:445-451.

$\rightarrow$ Harada T, W Kurahashi, M Yanai, Y Wakasa, T Satoh 2005 Involvement of cell proliferation and cell enlargement in increasing the fruit size of Malus species. Sci Hortic 105:447-456.

Homutová I, J Blažek 2006 Differences in fruit skin thickness between selected apple (Malus domestica Borkh.) cultivars assessed by histological and sensory methods. Hortic Sci (Prague) 33:108-113.

$\rightarrow$ Hong YP, SK Lee, YM Park, HS Park 2008 Developmental anatomy and features of the exocarp as related with fruit skin disorders in 'niitaka' pear fruit. J Jpn Soc Hortic Sci 77:382-387.

$\rightarrow$ Huang XM, HB Huang 2001 Early post-veraison growth in grapes: evidence for a two-step mode of berry enlargement. Aust J Grape Wine Res 7:132-136.

Jeffree C 2006 The fine structure of the plant cuticle. Pages 11-125 in M Riederer, C Müller, eds. Biology of the plant cuticle. Blackwell, Oxford.

Jiménez R, P Rallo, MP Suárez, AM Morales-Sillero, L Casanova, HF Rapoport 2012 Cultivar susceptibility and anatomical evaluation of table olive fruit bruising. Acta Hortic 924:419-424.

$\rightarrow$ King GA, KG Henderson, RE Lill 1987 Growth and anatomical and ultrastructural studies of nectarine fruit wall development. Bot Gaz 148:443-455.

King JR 1938 Morphological development of the fruit of the olive. Hilgardia 11:437-458.

Knee M 2002 Fruit quality and its biological basis. Blackwell, Oxford.

$\rightarrow$ Kubo T, S Hiratsuka 1999 Histological study on rind roughness of Satsuma mandarin fruit. J Jpn Soc Hortic Sci 68:101-107.

Lavee S 1986 Olive. Pages 261-276 in SP Monselise, ed. Handbook of fruit set and development. CRC, Boca Raton, FL.

$\rightarrow$ Legland D, F Guillon, K Kiêr, B Bouchet, MF Devaux 2010 Stereological estimation of cell wall density of DR12 tomato mutant using 3-dimensional confocal imaging. Ann Bot 105:265-276. 
$\rightarrow$ Lemaire-Chamley M, J Petit, V Garcia, D Just, P Baldet, V Germain, M Fagard, M Mouassite, C Cheniclet, C Rothan 2005 Changes in transcriptional profiles are associated with early fruit tissue specialization in tomato. Plant Physiol 139:750-769.

$\rightarrow$ Lescourret F, M Génard, R Habib, S Fishman 2001 Variation in surface conductance to water vapor diffusion in peach fruit and its effects on fruit growth assessed by a simulation model. Tree Physiol 21:735-741.

$\rightarrow$ Manandhar JB, GL Hartman, TC Wang 1995 Anthracnose development on pepper fruits inoculated with Colletotrichum gloeosporioides. Plant Dis 79:380-383.

Marcelis LFM, LRB Hofman-Eijer 1993 Cell division and expansion in the cucumber fruit. J. Hortic Sci 68:665-671.

$\rightarrow$ Mintz-Oron S, T Mandel, I Rogachev, L Feldberg, O Lotan, M Yativ, $\mathrm{Z}$ Wang, et al. 2008 Gene expression and metabolism in tomato fruit surface tissues. Plant Physiol 147:823-851.

Mulas M 1994 Genetic variability of histological characteristics in olive fruits. Acta Hortic 356:70-73.

Olmstead JW, AF Iezzoni, MD Whiting 2007 Genotypic differences in sweet cherry fruit size are primarily a function of cell number. J Jpn Soc Hortic Sci 132:697-703.

$\rightarrow$ Opara LU 2007 Bruise susceptibilities of 'Gala' apples as affected by orchard management practices and harvest date. Postharvest Biol Technol 43:47-54.

$\rightarrow$ Ouattara S, G Loum, A Clément 2011 The image analysis, tools for measuring quality criteria of apples by characterization of its cellular structure. Asian J Appl Sci 4:286-296.

$\rightarrow$ Quilot B, M Génard 2008 Is competition between mesocarp cells of peach fruits affected by the percentage of wild species (Prunus davidiana) genome? J Plant Res 121:55-63.

Romig WR 1995 Selection of cultivars for lightly processed fruits and vegetables. HortScience 30:38-40.

Roth I 1977 Fruits of the angiosperms. Gebrüder Bornträger, Berlin.

Ruzin S 1999 Plant microtechnique and microscopy. Oxford University Press, New York.

Sakai WS 1973 Simple method for differential staining of paraffin embedded plant material using toluidine blue O. Stain Technol 48: 247-249. $\rightarrow$ Schlosser J, N Olsson, M Weis, K Reid, F Peng, S Lund, P Bowen 2008 Cellular expansion and gene expression in the developing grape (Vitis vinifera L.). Protoplasma 232:255-265.

Schroeder CA 1953 Growth and development of the Fuerte avocado fruit. Proc Am Soc Hortic Sci 61:103-109.

Scorza R, LG May, B Purnell, B Upchurch 1991 Differences in number and area of mesocarp cell between small- and large-fruited peach cultivars. J Am Soc Hortic Sci 116:861-864.

$\rightarrow$ Sekse L 1995 Fruit cracking in sweet cherries (Prunus avium L.). Some physiological aspects: a mini review. Sci Hortic 63:135141.

$\rightarrow$ Simons RK, MC Chu, CC Doll 1980 Physiological disorders of the apple at mid-season stage of development. Sci Hortic 13:227233.

Skene DS 1966 The distribution of growth and cell division in the fruit of Cox's Orange Pippin. Ann Bot 30:493-512.

$\rightarrow$ Sterling C 1953 Developmental anatomy of the fruit of Prunus domestica L. Bull Torrey Bot Club 80:457-477.

$\rightarrow$ Wang XG, MW Johnson, KM Daane, VY Yokoyama 2009 Larger olive fruit size reduces the efficiency of Psyttalia concolor as a parasitoid of the olive fruit fly. Biol Control 49:45-51.

$\rightarrow$ Yamaguchi M, T Haji, M Miyake, H Yaegaki 2002 Varietal differences in cell division and enlargement periods during peach (Prunus persica Batsch) fruit development. J Jpn Soc Hortic Sci 71: 155-163.

$\rightarrow$ Yamaguchi M, T Haji, H Yaegaki 2004 Differences in mesocarp cell number, cell length, and occurrence of gumming in fruit of Japanese apricot (Prunus mume Sieb. et Zucc.) cultivars during their development. J Jpn Soc Hortic Sci 73:200-207.

$\rightarrow$ Yamaguchi M, I Sato, A Watanabe, M Ishiguro 2003 Cultivar differences in exocarp cell growth pattern at apex, equator, stalk cavity and suture during fruit development in sweet cherry (Prunus avium L.). J Jpn Soc Hortic Sci 72:465-472.

$\rightarrow$ Zeebroeck MV, E Tijskens, E Dintwa, J Kafashan, J Loodts, J De Baerdemaeker, H Ramon 2006 The discrete element method (DEM) to simulate fruit impact damage during transport and handling: case study of vibration damage during apple bulk transport. Postharvest Biol Technol 41:92-100. 